\title{
Constraint-based Naturalistic Decision Making in Mission Planning Teams
}

\author{
Neville A. Stanton \\ School of Civil Engineering and the Environment \\ University of Southampton, Highfield \\ Southampton, SO17 1BJ, UK \\ N.Stanton@soton.ac.uk \\ Daniel P. Jenkins \\ School of Engineering and Design, Brunel University, \\ Uxbridge, Middlesex, UB8 3PH, UK \\ Daniel.Jenkins@brunel.ac.uk
}

\author{
Guy H. Walker \\ School of Civil Engineering and the Environment \\ University of Southampton, Highfield \\ Southampton, SO17 1BJ, UK \\ G.Walker@soton.ac.uk \\ Paul M. Salmon \\ Human Factors Group, MUARC, \\ Monash University, Victoria 3800, Australia \\ paul.salmon@muarc.monash.edu.au
}

\begin{abstract}
Motivation - To understand the factors acting upon decision making of military planners prior to the introduction of digital planning systems. Research approach - Participant-observation by the research team and direct observation of the planning process on exercises. Findings - Many different disciplines contribute to the planning process in a co-operative and collaborative manner. Each stage in the planning process results in a further set of constraints being applied, each of which offer successive refinement of the plan. Research limitations/Implications - The research is limited to land-based military planning. Originality/Value - This research is based on field observation of military planners with tight deadlines and a non-compliant opposing force. Take away message - 'Military planning seems to be more about identification of relevant constraints than optimization of decisions' .
\end{abstract}

Keywords

Planning, constraints, military, teams, digitization

\section{MISSION PLANNING CONSTRAINTS}

Mission failure is often thought to be the result of poor mission planning (Levchuk et al, 2002), which places considerable demands on the planners and the planning process. This observation is further confounded by the two general principles of warfare. Mission planning has to be a continuous, iterative and adaptable process, optimising mission goals, resources and constraints (Levchuck, 2002). Roth et al (2006) argue that the defining characteristic of command and control is the continual adaptation to a changing environment. Constant change in the goals, priorities, scale of operations, information sources and systems being used means that the planning systems need to be extremely adaptable to cope with these changes. According to Klein and Miller (1999) there are many constraints acting on mission planning, including scarcity of resources, time pressure, uncertainty of information, availability of expertise, and the structure of the tasks to be undertaken. Mission planning requires knowledge of the domain, objects in the domain and their relationships as well as the constraints acting on the domain, the objects and their relations (Kieweit et al, 2005). Klein and Miller (1999) also note that the planning cycles can range from a couple of hours to a few days depending upon the complexity of the situation and the time available.

\section{OSERVATIONS}

The mission planning process has been observed by the authors at the Land Warfare Centre at Warminster and on training exercises in Germany. The observations at Warminster have been both as participant-observers and as normal observers. The planning is undertaken in a 'public' environment when various people contribute and all can view the products. This 'public' nature of the products is particularly useful at the briefings, which encourages collaboration and cooperation. It also helps to focus the planners' minds on the important issues and the command intent. The process of mission planning is a collaborative and co-operative process, both in terms of the contribution to the products and the verbal interactions. It is also very obvious that the planning team surrounds themselves with the planning artefacts. Maps, overlays, white-boards, and flip-charts literally adorn every surface. The plan is literally constructed in the space between these artefacts, as information is collected, transformed and integrated from the cognitive artefacts and the interactions between the planning team. The training that planners undergo reinforces the fact that the information 
needs to be 'public', for all to see and interact with. The planning process appears to focus on identifying the constraints (such as the mission, the enemy, the environment, the resources and assets) to help define the possible courses of action. The process also requires an understanding of enemy doctrine and tactics to anticipate their likely behaviour and responses as well as military experience to know what effects are likely to achieve the desired outcome. Although it is difficult to quantify, there is certainly the opportunity for creativity in the way in which the plan is constructed. The planning team are continually trying to identify ways in which they can get the most from their finite resources and assets as well as preventing the enemy from anticipating their strategy.

\section{IMPLICATIONS FOR DIGITISATION}

Moves have been made to develop digital system to support the planning processes (see Riley et al, 2006 and Roth et al, 2006 for just two examples). The focus of these activities has been on the products of the planning process for distribution between the planning team and to other people in the network. The challenge to system designers has been to preserve the collaborative, public and creative parts of the planning process as well as supporting different levels of plan fidelity (which will depend on the time available to develop the plan). Perhaps the biggest challenge is to decide what needs to be digitised and what form this digitisation should take. Given that military planning teams have invested considerable effort in developing and refining their planning skills using the traditional media, it would seem appropriate to try and support these activities rather than requiring them to develop a new set of skills. The planning process has evolved over centuries of refinement and improvement (Clausewitz, 1832). Roth et al (2006) argued that much insight may be gleaned from studying the work-arounds and home-grown cognitive artefacts that are being used by command and control teams (such as the so-called 'cheat-sheets' and sticky notes). The traditional analogue planning process (as described earlier) is certainly abundant with potential metaphors, such as overlays, stickies, routes, COAs and so on. It is worth considering if the conventional media could be captured digitally (by camera, scanner, or other means) if they need to be transmitted as electronic documents with orders or reports, or for wider distribution. As a general design principle, the production of electronic documents should be at least as easy as the production of their analogue equivalents. Baxter (2005) is wary of the inexorable trend to digitise and concerned by the history of technology failing to deliver expected benefits, this is not just linked to military experience (Sinclair, 2007). Baxter argued that very few people understand the interrelated issues for technology, operations and human factors (being conversant in just one of these topics is not sufficient). Transformational approaches are likely to cause more problems than they solve.

\section{ACKNOWLEDGMENTS}

This work from the Human Factors Integration Defence Technology Centre was part-funded by the Human Sciences Domain of the UK Ministry of Defence Scientific Research Programme.

\section{REFERENCES}

Baxter, R. (2005) Ned Ludd encounters Network Enabled Capability. RUSI Defence Systems, (Spring 2005), 34-36.

Clausewitz, C. Von (1832) On War (found at:

http://www.clausewitz.com/CWZHOME/VomKriege2/ONWARTOC2.HTML accessed on: 15 August 2007)

Kiewiet, D. J., Jorna, R. J. And Wezel, W. V. (2005) Planners and their cognitive maps: an analysis of domain representation using multi-dimensional scaling. Applied Ergonomics, 36, 695-708.

Klein, G. and Miller, T. E. (1999) Distributed planning teams. International Journal of Cognitive Ergonomics, 3 (3), 203-222.

Levchuk, G. M., Levchuk, Y. N., Luo, J., Pattipati, K. R. and Kleinman, D. L. (2002) Normative design of organisations - Part I: Mission Planning. IEEE Transactions on Systems, Man and Cybernetics - Part A: Systems and Humans, 32 (3), 346-359.

Riley, J. M., Endsley, M. R., Bolstad, C. A. and Cuevas, H. M. (2006) Collaborative planning and situation awareness in Army command and control. Ergonomics, 49 (12-13), 1139-1153.

Roth et al (2006) Evolvable work-centred support systems for command and control. Ergonomics, 49 (7), 688-705.

Sinclair, M. A. (2007) Ergonomics issues in future systems. Ergonomics, 50 (12), 1957-1986. 